\title{
Porphyrin-Dye Sensitized Solar Cell Utilizing Nitroxide Radical Mediator
}

\author{
Takaya Murakami, Fumiaki Kato, Kenichi Oyaizu, and Hiroyuki Nishide ${ }^{1)}$ \\ Department of Applied Chemistry, Waseda University, \\ Shinjuku, Tokyo 169-8555, Japan
}

Keywords: Nitroxide Radicals, Dye Sensitized Solar Cell, Porphyrin

\section{Introduction}

Dye-sensitized solar cells (DSSCs) are attractive energy source in academic and industrial field. The most effective DSSC was reported by Grätzel at et al. in 1991, the total conversion efficiency was over $11 \%$ in standard global AM 1.5 solar light in standard condition.[1] It was composed dye- sensitized nanocrystaline porous semiconductor metal oxide and $I^{\prime} I_{3}^{-}$electrolyte. The dye-sensitizer is excited by Sun light absorption, and its excited electron inject to semiconductor's conduction band. The dye is regenerated by $I$ in electrolyte. The redox couple of $I / I_{3}$ propagates charge to counter electrode. The $I / I_{3}^{-}$is known good redox mediator for DSSCs. However the redox potential of $I / I_{3}{ }^{-}(0.4$ $\mathrm{V}$ vs SHE) is different from that of dye-sensitizer. The large potential gap results energy loss during dye regeneration, and makes DSSC properties,

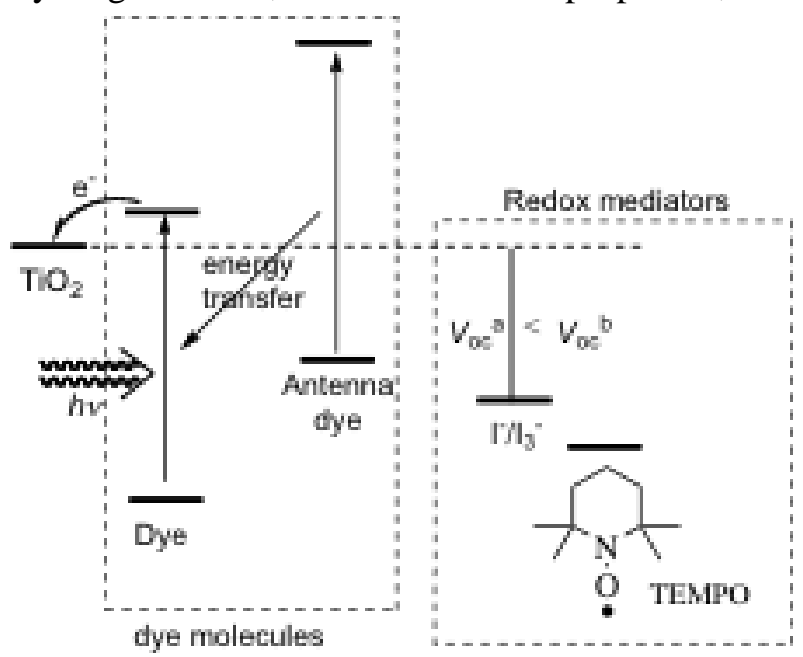

Figure 1. Schematic image of DSSC utilizing nitroxide mediator and hetero-dye sensitizer. especially open circuit voltage $\left(V_{\mathrm{oc}}\right)$ lower.

To improve this mismatch, a new redox mediator having appropriate potential is necessary material. In order to achieve the higher photovoltaic performance, a lot of dye sensitizers such as ruthenium complex, indoline derivatives and so on have been synthesized and modified to exhibit much wider and stronger absorption by changing of their ligands or substituent groups. Porphyrin derivatives are the attractive candidates for novel dye sensitizer due to their strong absorbance in visible region. Then, the antenna dye molecules were also examined to achieve the effective light-harvest.

2,2,6,6-Tetramethylpiperidine-1-oxyl(TEMPO ) is widely known as an oxidation catalyst for alcohol. And some nitroxide radical molecules have been applied to organic secondary battery, organic radical memory, and hole-transporting material because of its rapid and reversible redox property. Nitroxide radical molecules have great potential as DSSC's redox mediator. Here, we report the application of nitroxide radical mediator and porphyrin dye to DSSC. In the
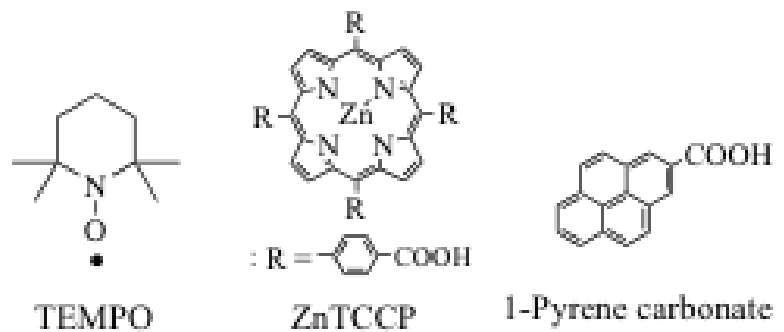

Figure 2. Chemical structure of TEMPO, ZnTCCP, and 1-pyrene carbonate. 
Present paper, we use a typical porphyrin 5,10,15,20-tetra(4-calboxyl- pheny)porphyrin$\mathrm{Zn}$ (II) (ZnTCCP) as a dye sensitizer and 1-pyrene carbonate as light-harvesting antenna dye.

\section{Experimental}

TEMPO, $N$-methylbenzimidazole (NMB), lithium bis(trifluoro methanesulfonyl)imide (LiTFSI), 1-pyrene carbonate and ZnTCCP were purchased by Tokyo Kasei Inc.. The acetonitrile electrolytes contained $1 \mathrm{M}$ nitroxide radical molecule, 1.6 M NMB, and 0.5 M LiTFSI. In electrolyte, $0.1 \mathrm{M} \mathrm{NOBF}_{4}$ was also added to make radical cation as redox couple. UV-vis spectra and cyclic voltammetry (CV) were recorded by using JASCO V-550 UV/vis spectrophotometer and BAS 100B/W electro- chemical analyzer, respectively.

Test cells were fabricated as follows. $\mathrm{A} \mathrm{TiO}_{2}$ nanoparticle layer $(1.5 \mu \mathrm{m})$ and a light scattering layer were fabricated on a fluorine-doped tin oxide-coated glass substrate. ${ }^{11}$ The resulting layer was heated at $450^{\circ} \mathrm{C}$ for $2 \mathrm{~h}$ in air. Dye adsorption was carried out by immersing the $\mathrm{TiO}_{2}$ electrode into two solutions for $20 \mathrm{~h}$ at room temperature. The dye solution A was a $0.3 \mathrm{mM}$ ZnTCCP and 3 $\mathrm{mM}$ deoxychoalic acid in tert-butyl alcohol $/ \mathrm{CH}_{3} \mathrm{CN}(1 / 1 \mathrm{v} / \mathrm{v})$, and the dye solution $\mathrm{B}$ was a $0.3 \mathrm{mM} \mathrm{ZnTCCP}$ and $3 \mathrm{mM}$ deoxychoalic acid, and $0.3 \mathrm{mM}$ 1-pyrene carbonate in tert-butyl alcohol $/ \mathrm{CH}_{3} \mathrm{CN} \quad(1 / 1 \quad \mathrm{v} / \mathrm{v}) \quad$ To add excess deoxychoalic acid, the porphyrin dye absorbed on $\mathrm{TiO}_{2}$ could avoid the excimer quenching to inhibit $\pi-\pi$ stacking state of the dyes. 1-Pyrene carbonate, which achieves effective energy transfer to porphyrin dye, was added as an antenna molecule to emphasize the photovoltaic performance. The counter electrode consisted of a platinum-coated glass plate. Into the fabricated cell assembly was then introduced a solution of the nitroxide mediator which was a $\mathrm{CH}_{3} \mathrm{CN}$ solution of $0.25 \mathrm{M}$ TEMPO, $0.05 \mathrm{M} \mathrm{NOBF}_{4}, 1.6$ $\mathrm{M}$ lithium bis(trifluoromethanesulfonyl)imide, and $0.25 \mathrm{M} \quad N$-methyl-benzimidazole. The photovoltaic performances were measured using a Keithley 2400 source meter and an AM 1.5 solar simulator (YSS-40S, Yamashita Denso Co.) as the light source.

\section{Results and Discussion}

Cyclic voltammetry of TEMPO exhibited reversible redox waves at $0.66 \mathrm{~V}$ vs. $\mathrm{Ag} / \mathrm{AgCl}$. The oxidation potential was suitable to regenerate the porphyrin dye cation. The diffusion coefficient was $7.5 \times 10^{-5} \mathrm{~cm}^{2} / \mathrm{s}$, and the rate constant of electrode reaction was $3.3 \times 10^{-2} \mathrm{~cm} / \mathrm{s}$. These values were same order of $I / I_{3}$. UV-vis absorption of these radical molecules was negligible and avoided the loss induced by light absorption of electrolyte. These results suggest that radical molecules have possibility of an effective dye regeneration and charge propagation.

Though the absorption of ZnTCCP didn't overlap to that of 1-pyrene carbonate, the emission spectra of them was existed very close region. The $\mathrm{UV}$-vis spectrum of these dyes on $\mathrm{TiO}_{2}$ exhibited a stronger and broaden peak. These results implied that the energy transfer pyrene to ZnTCCP might be effective system, and 1-pyrene was novel antenna dye for ZnTCCP to use UV reagion light. The fluorescence lifetime of ZnTCCP in THF was decreased by addition of the 1-pyrene carbonate. The rapid energy transfer was occurred between ZnTCPP and pyrene, and the energy transfer rate constant was $1.5 \times 10^{12} \mathrm{M}^{-1} \mathrm{~s}^{-1}$ estimated by the Stern-Volmer plots.

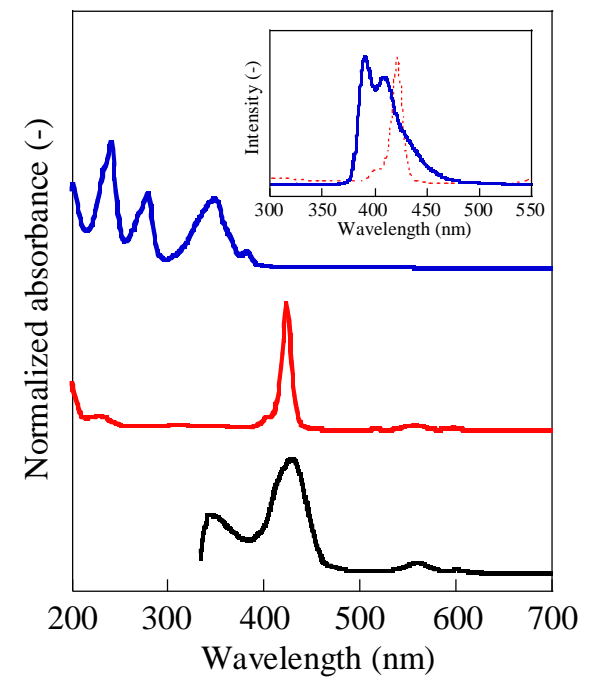

Figure 3. Absorption spectra of (a) 1-pyrene carbonate, (b) ZnTCCP in methanol and (c) 1-pyrene and ZnTCCP absorbed on $\mathrm{TiO}_{2}$ electrode commonly from acetnitrile/t-butanol solution with a molar ratio of $1 / 1$. Inset: Fluorescence spectrum of 1-pyrene carbonate (solid) and absorption spectrum of ZnTCCP (dotted) in methanol. 


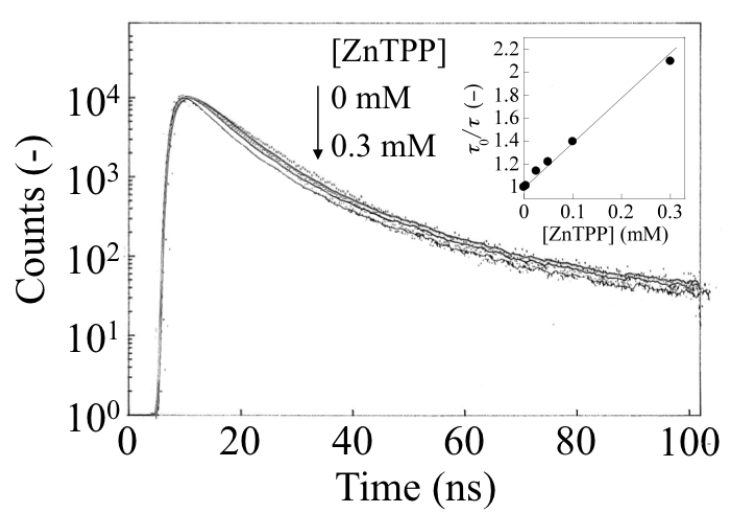

Figure 4. Time-resolved emission decays for 1-pyrene carbonate with ZnTCCP in THF. Inset; Stern-Volmer plots for the 1-pyrene fluorescence quenching by ZnTCCP.

Current density-voltage characteristics were shown in Figure. 5. DSSC using TEMPO and ZnTCCP with deoxychoal acid gave maximum properties; $V_{\text {oc }}$ was $0.65 \mathrm{~V}$, current density was 2.3 $\mathrm{mA} / \mathrm{cm}^{2}$, fill factor was 0.74 , and conversion efficiency was $1.1 \%$. The DSSC which is common absorption of ZnTCCP and pyrene was decrease of photovoltaic performance. This decrease gave less absorption of ZnTCCP due to excess pyrene dye.

\section{Acknowledgement}

This work was partially supported by Grants-in-Aid for Scientific Research (19105003 and 21106519) from MEXT, Japan, and Research Project "Radical Polymers" at Advanced Research Institute for Science \& Engineering, Waseda University. We thank Mr. T. Sekiguchi and Dr. S. Kambe in Advanced Technologies Development Laboratory of Panasonic Electric Works Co. for their helpful discussion.

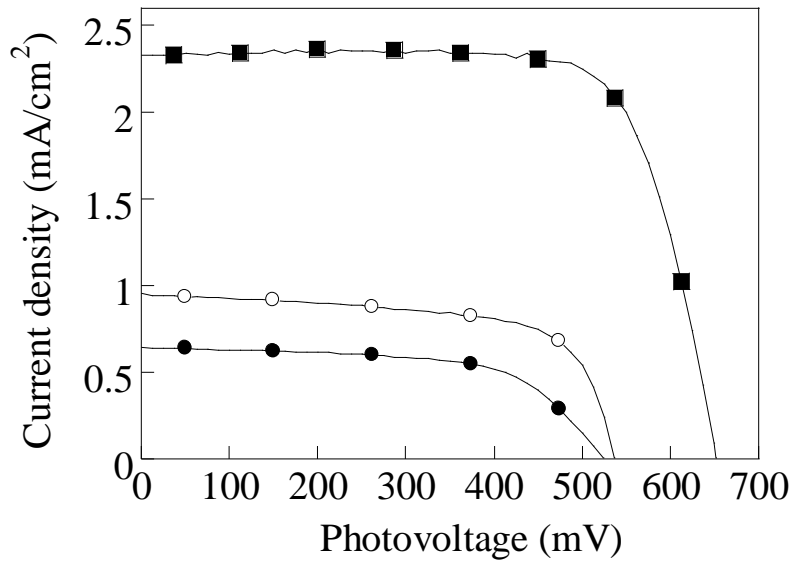

Figure 5. Current density-voltage $(J-V)$ characteristics for the ZnTCCPP-sensitized solar cells using $0.1 \mathrm{M}$ TEMPO as the redox mediators and a $1.5 \mathrm{~mm}$ thick $\mathrm{TiO}_{2}$ layer on the FTO as the electron transport layer, measured under an AM1.5 full sunlight $\left(100 \mathrm{mWcm}^{-2}\right)$ irradiation.

\section{References}

1. B. C. O'Regan, M. Grätzel, Nature, 353 (1991) 737.

2. M. K. Nazeeruddin, F. De Angelis, S. Fantacci, A. Selloni, G. Viscardi, P. Liska, S. Ito, T. Bessho, M. Grätzel, J. Am. Chem. Soc., 127 (2005), 16 835.

3. H. Nishide, K. Oyaizu, Science, 319 (2008), 737

4. Y. Yonekuta, K. Oyaizu, H. Nishide et al., J. Am. Chem. Soc., 129 (2007), 14128

5. Kurata T., Koshika K., and Nishide H., Photopolym. Sic. Tech., 16 (2003) 298.

6. T. Kurata, K. Koshika, F. Kato, J. Kido and H. Nishide Chem. Commun., 2007, 2986- 2988

7. Z. Zhang, P. Chen, T. N. Murakami, S. M. Zakeeruddin, and M. Grätzel, Adv. Funct. Mater., 18 (2008), 341 